\title{
Review
}

\section{Existing Biosensing Platforms for the Nucleotide Markers Detection}

\author{
Elena Dmitrienko ${ }^{1, *}$, Inna Pyshnaya ${ }^{1}$, Fedor Dultsev ${ }^{2}$, Andrey Tronin ${ }^{3}$ and Dmitrii Pyshnyi 1,* \\ 1 SB RAS, Institute of Chemical Biology and Fundamental Medicine, 630090 Novosibirsk, Russia, \\ niboch@niboch.nsc.ru \\ 2 SB RAS, A.V. Rzhanov Institute of Semiconductor Physics, 630090 Novosibirsk, Russia; ifp@isp.nsc.ru \\ 3 MBU-Technology, Llc., 630090 Novosibirsk, Russia; info@mbu-tech.com \\ * Correspondence: pyshnyi@niboch.nsc.ru (E.D.); elena.dmitrienko@niboch.nsc.ru (D.P.)
}

\begin{abstract}
In review, the operating principles of the most common bio sensing devices, detection methods and the identification sensitivity of analyzed molecules were shown. The central focus was done on hybridization analysis of nucleic acids (NA), which are considered to be one of the most important analytes in terms of diagnostic point of view. Constructions enabling to transfer the fact of formation of nucleotide probe/target complex in to detectable signal by optical, electrochemical or micromechanical (piezoelectric) sensors were presented in this review.
\end{abstract}

Keywords: hybridization analysis; nucleic acids; optical biosensors; electrochemical biosensors; micromechanical (piezoelectric) sensors

\section{Introduction}

Solving fundamental and practical problems of contemporary science in the field of molecular biology, biotechnology and molecular diagnostics, a special attention is paid to researches aimed at creating easy in regards to experiments, inexpensive, sensitive and selective analytical methods that ensure a rapid detection of biomolecular markers in a sample [1,2] . Devices for biosensing are analytical systems that combine qualities mentioned above. The biosensors' operation basis is a process of high-avid detection of the molecules analyzed [3]. The role of the biosensor is to provide a platform for transferring the analyte detection fact (complex formation of nucleotide probe/target, antigen/antibody, ligand/receptor, etc.) to a hardware or visually detectable signal [4].

Biochips are one of the most famous examples of devices for biosensing [5, 6]. Developing the device for biosensing requires negotiation of many factors among which an important place is made to ensure the effectiveness of implementing a specific interaction between the biosensor detecting layer and the molecule analyzed. For accurate signal detection, biosensors must have a high sensitivity and a specificity towards the components defined as well as the ability to regenerate that makes it possible to re-use the sensor without significant loss of its effectiveness. Thus, the sensor sensitivity mainly depends on the method detecting the complex formed, and its specificity is identified by interaction of the analyte and molecules immobilized on the biosensor and by the interaction detection method.

Development of devices for biosensing has become a topical subject for fundamental and applied researches. The literature shows a vast variety of approaches to the analysis of biomolecules such as nucleic acids and proteins with various substrates and analytical signal imaging methods. Below, there are shown the operating principles of the most common biosensing devices, detection methods and the analyzed molecules identification sensitivity.

The central focus (a target of the review) was on hybridization analysis of nucleic acids (NA), one of the most important analytes in terms of diagnostic point of view. 
A biosensor is an analytical unit where a detecting element comprises a material capable of biomolecules specific binding [e.g., 7-10]. The biosensensing systems operation is based on the implementation of various specific physical and chemical and/or biochemical processes: the formation of a hybridization complex between complementary nucleic acid sequences, an enzyme-substrate complex, a ligand-receptor complex (antigen/antibody) formation or accumulation of transformation products composed of such intermolecular associates.

Detecting element can directly react to the analyte or generate a signal caused by the analyte content in the sample. Further on, based on a particular physical principle, the formation of a specific complex between the detecting elements and the analyte is transferred to the detected signal. There are a large number of physical transmitters (transducers) used in the biosensensing systems: optical, electrochemical, micromechanical, spectroscopic, thermal, piezoelectric, and other transmitters.

Subject to a condition, all approaches to the analyte detection that are used in sensing technologies can be divided into two fundamentally different types: without reporter groups ('label-free') [11] and with reporter groups [12].

In the first case, the fact of the binding the analyzed molecule with the detecting sensor element able to be registered is detected directly. In the second case, reporter groups ensuring to detection during or immediately after the specific complex formation can serve as signal generators. There are a direct method of reporter group detection and a mediated imaging method (e.g., after the conduction of enzyme-dependent reactions), based on the conversion of specific substrates providing the recorded signal. The analyzed target in the sample can be found both by occurring on the detected signal from the reporter group and by 'switching off' of the original signal (e.g., fluorescence quenching). The compound used as the label has to meet the general requirements: ease introduction to the system, detection in small quantities, and stability under analysis and storage conditions [13].

According to the type of the detected signal, the current devices for biosensing can be classified into:

- optical devices for biosensing based on the change in characteristics of the light flux under specific binding of the analyte with the detecting element, for example, under absorption [7], fluorescence [14], surface plasmon resonance [15], and other optical phenomena;

- electrochemical devices for biosensing, based on the measurement of such cell characteristics as potential (potentiometric) [7], oxidation current strength or electroactive species recovery (amperometric, voltammetric) [11] or the electrical conductivity (conductometric) [16];

- micromechanical devices for biosensing $[17,18]$, based on the change in the surface characteristics depending on the weight of substance adsorbed thereon.

\section{Optical biosensors}

Optical sensors are one of the major categories of chemical sensors; their operation is based on the analysis of the light absorption and reflection (including surface plasmon resonance) and luminescence. Thus, the analyte detection is based on registration of the changes in the optical media characteristics (refractive index, reflection index, etc.) due to the analytes concentration. As may be required, optical sensors make it possible to carry out the signal detection in a real-time mode, which ensures not only a possibility to record the interaction of the molecules, but also to evaluate the kinetic characteristics of the process. There are a number of optical biosensors for detecting the nucleic acids (NA); they include fluorescent [12], chemiluminescent compounds [19], gold and silver nanoparticles [20] as reporter groups.

The most common reporter groups in the NA analysis are fluorescent dyes (fluorophores) with an ability to emit light while being excited by a short-wavelength light [12]. Methods to generate a 
fluorescent signal are very diverse and often determined by a specific task. In the NA analysis for the signal detection in real-time mode, the principles of mutual influence of fluorophores are used, such as fluorescence resonance energy transfer (FRET) [21] - a method based on the energy transfer between two fluorophores, one of which is a donor, and the other is an energy acceptor. Thus, under binding of two fluorophores (the donor (Fd) and the acceptor (Fa)) (for example, in 'sandwich' hybridization of two oligonucleotide probes on complementary DNA target), upon excitation of the donor ( $\mathrm{Fd})$, instead of its fluorescence, an energy transfer to the acceptor $(\mathrm{Fa})$ will occur and the donor fluorescence quenching or the appearance of a long wavelength fluorescent signal from the acceptor (Figure 1) will be observed.

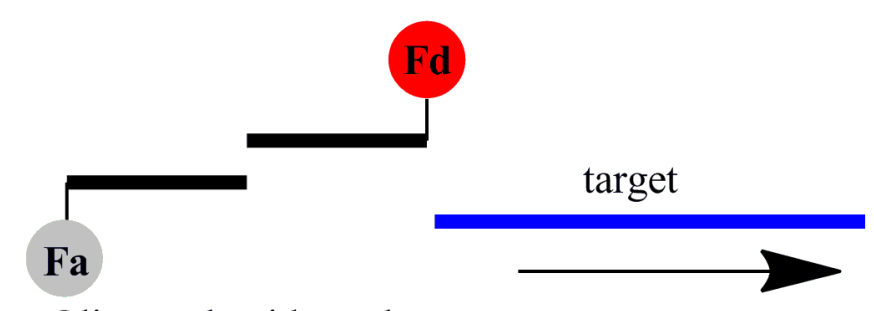

Oligonucleotide probes
Hybridization complex

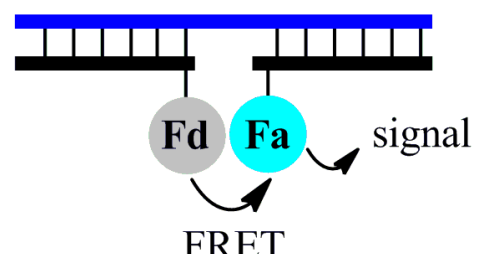

Figure 1. Fluorescent resonance energy transfer (FRET) diagram.

Examples for a donor-acceptor fluorophores pair are fluorescein, rhodamine, and their derivatives [21].

FRET implementation can also be using specific probes such as 'molecular beacon' - hairpin oligonucleotides consisting of a sequence complementary to the DNA target, and the self-complementary end portions attached to the fluorophore and quencher on the 5'- and 3 '-ends respectively (Figure 2).

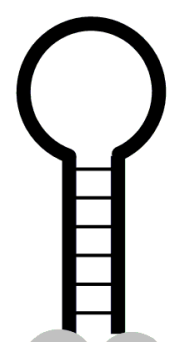

Fd Fa

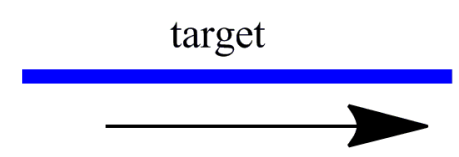

Oligonucleotide probe

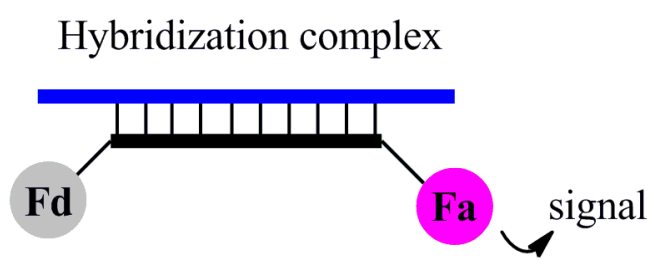

Figure 2. Diagram of DNA analysis with the participation of 'molecular beacons'.

In the natural state, both ends of the 'molecular beacon' are in close proximity to each other resulting in quenching of fluorescence. In the presence of DNA target, molecular beacons undergo conformational changes forming a hybridization complex; a fluorophore $(\mathrm{Fd})$ and a quencher $(\mathrm{Fa})$ are no longer in contact with each other, and an increase in fluorescence intensity is observed [22]. The 'molecular beacons' are known to be used in the methods of heterophase hybridization for the development of DNA sensors [23]. The high specificity of DNA analysis with usage of 'molecular beacons' makes it possible to create test system based thereon determing not only the presence of a specific sequence but local disturbances in its structure [24]. 
In addition to the fluorescent dyes as reporter groups, quantum dots are used. That are semiconductor nanoparticles (e.g., ZnS, CdSe) [25] having its own fluorescence, high chemical and photochemical stability, a wide range of excitation.

The effect of the Surface-Enhanced Raman Scattering Spectroscopy [26] is one of the current methods to detect and identify the biomolecules with high sensitivity pending to the detection of single molecules. Huge (in some cases up to 10 orders of magnitude) increase in Raman scattering by the molecules located near the surface of metal substrates is caused by two mechanisms: an electromagnetic one associated with an increase in the local electromagnetic field near the surface, and a molecular one, i.e., due to the formation of new excited states of a molecule-metal complex.

As such surfaces, metal films with high roughness can be used (e.g., electrodes in the electrochemical cell after etching their surface in the redox cycle, glass surfaces coated with a silver layer, the metal nanoparticles in colloidal suspensions, etc.). Surface-Enhanced Raman Scattering Spectroscopy spectra were recorded using standard equipment to obtain the Raman spectra [27].

Detection of molecules by the SERS method has a number of advantages over the fluorescence. The Raman Dye (a SERS-active molecule) can be fluorescent or non-fluorescent and its slight chemical modification can lead to the formation of the dye with Raman spectrum sharply differing from the original one, even when both dyes have virtually indistinguishable fluorescent spectra. In addition, absorption bands in the ultraviolet region of the spectrum as well as emission bands of fluorescent dyes are rather broad; the molecular and maximum numbers of fluorophores that can be used in one experiment, are limited by 3 or 4 residues. The broad light absorption and emission bands by fluorophores can overlap. In the Surface-Enhanced Raman Scattering Spectroscopy spectrum, the same dyes have narrower signals that potentially makes it possible to use a greater number of reporter groups in the system, and, hence, to identify a larger number of analytes in a multiplex assay [28]. The identification of the analyzed DNA sequence based both on the appearance of the Surface-Enhanced Raman Scattering Spectroscopy signal [29], and its disappearance [30], for example, by using hairpin DNA probes carrying the SERS-active label and immobilized on the gold nanoparticles (similar to the 'molecular beacons') is possible (Figure 3).
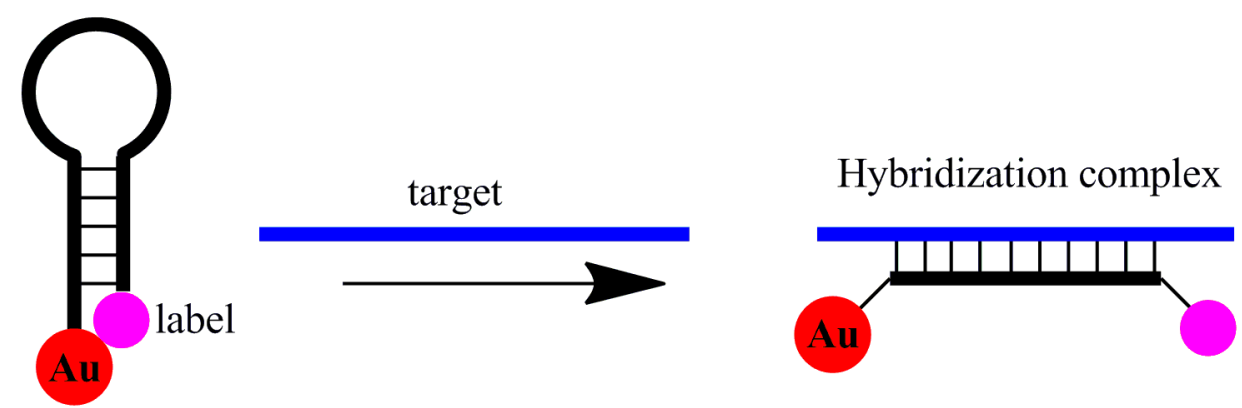

\section{Oligonucleotide probe}

Figure 3. Diagram of DNA analysis based on the signal loss of SERS Raman Scattering Spectroscopy [30].

Increasing the sensitivity analysis of DNA detection by SERS method is implemented using gold nanoparticles, and signal gain is sought by depositing silver metal on their surface (Figure 4) [28]. 


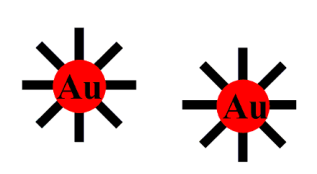

Oligonucleotide probe

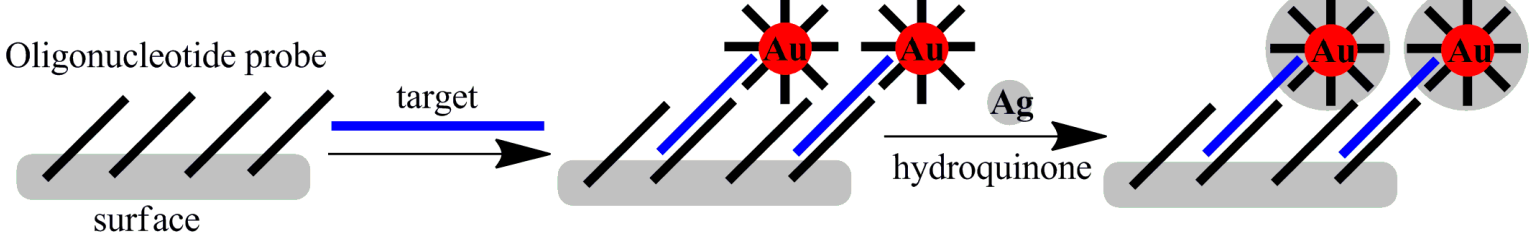

Figure 4. Diagram of DNA analysis by the Raman Scattering Spectroscopy comprising the step of the deposition of metallic silver on the gold particles surface [28].

Surface Plasmon Resonance (SPR) is used in the development of highly sensitive methods for detecting specific intermolecular interactions at the border of the sensor metallized layer and the analyzed solution [31]. Prisms applied as optical elements in the SPR method are typically made of quartz, whose sensor surface is covered by a thin metal film ( $\mathrm{Au}, \mathrm{Ag}, \mathrm{Al}$ or $\mathrm{Cu}$ ). The surface plasmons are implemented on the border of a rigid body (metal or semiconductor) and represent the quantum oscillations of surface charges arising at the interface under the influence of external electromagnetic fields. The surface plasmons can be excited by light or electron beams. The laser light passing through the prism is incident on the metal surface and reflected from it in all directions except the critical angle $\theta$. The $\theta$ value is strictly dependent on the coefficient of layer refraction adjacent to the sensor surface; it is changed due to the analyzed molecules on the surface. Thus, evaluating the changes of the critical angle, it is possible to determine the changes occurring on the sensor surface.

In case of constructing the DNA sensors using SPR, the NA probe is immobilized on the sensor surface; it detects the refractive index change after the formation of the complex with the analyzed DNA without the reporter groups. Fixing the refractive index changes in real time, it is possible to determine the amount of DNA target, to evaluate the kinetic parameters of the binding process. The sensitivity of SPR-mediated detection of the NA is about $10^{-9} \mathrm{M}$ [15], and in some cases by using gold nanoparticles, it can reach $\sim 10^{-15} \mathrm{M}[32]$.

Chemiluminescence (CL) is a luminescence implemented by a chemical reaction. CL has two stages: a chemical one, where the formation of the product reaction in the excited electronic state is formed, and a physical one, when the product emits a light under the transition to the electronic ground state. Chemiluminescence measurement of biological samples is a sensitive method to study the biomolecules; it is used in the laboratory and in clinical practice [33]. Chemiluminescence chemical activators are compounds entering into chemical reactions, e.g., with reactive oxygen intermediate or organic free radicals, which are formed into the molecules being in the excited unstable electronic state. Luminol and compounds close to his chemical structure can be considered as the well-known examples of such activators. Zero background glows and no need to light excitation are the advantages of such systems in comparison with the fluorescent methods. Often in chemiluminescent assay, there are applied the enzyme mediated detection system using enzymes such as horseradish peroxidase, [34], alkaline phosphatase, [19], glucose oxidase [35], etc. generating a chemiluminescent signal because of enzymatic conversion of specific substrates. For example, the chemiluminescent oxidation of luminol catalyzed by horseradish peroxidase in composition of conjugate with streptavidin was used for the detection of biotinylated DNA in the paper [34] (Figure 5). The detection limit of the DNA model sequence was $5 \times 10^{-11} \mathrm{M}$. 


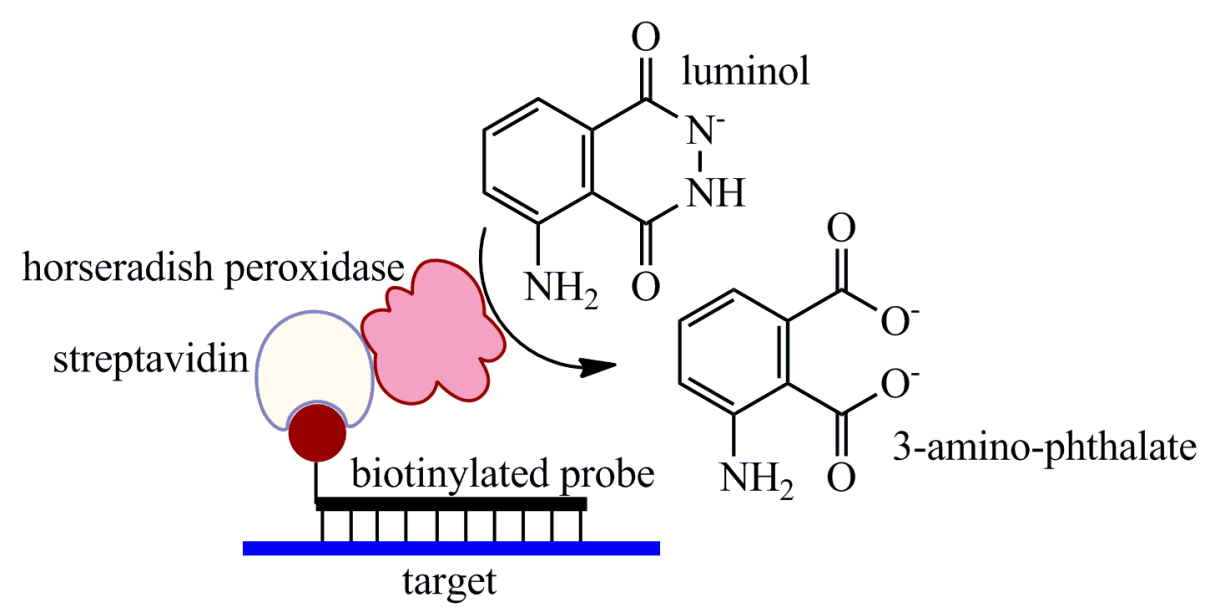

Figure 5. Driving chemiluminescent NA detection based on the oxidation of luminol catalyzed by horseradish peroxidase [34].

One should specially focus on the system detection of biomolecules based on the bioluminescence. As an analytical signal generators in this case, the photoproteins, such as obelin [36] or aequorin [37] may be considered singled out from bioluminescent organisms. Due to the high quantum yield of photochemical reactions, the possibility of obtaining the recombinant photoproteins and their stable conjugates with other biomolecules, as well as the availability of current photosensitive technique, such labels are successfully used in the analyzed systems to determine biomolecular markers [37-39], including DNA [36] . Bioluminescent detection systems can reliably detect the DNA sequence analyzed in a concentration of $10^{-11} \mathrm{M}[36]$.

One of the easiest ways of DNA detection is a colorimetric method based on determining the presence of a substance or its intensity on the solutions color concentration, which is determined visually or spectrophotometrically. The advantage of colorimetric analysis approaches is the ease. Colorimetric detection methods using enzymatic systems are similar to chemiluminescent methods, however, instead of the chemiluminescent substrates in this case they use the chromogenic substrates, in the enzymatic conversion of which an accumulation of colored products, such as blue precipitate upon alkaline phosphatase contact with BCIP substrates (5-bromo-4-chloro-3-indolyl phosphate disodium salt) and NBT (nitrotetrazolium blue) [40] is observed (Figure 6). Such a signal can be recorded visually as well. One should note, however, that the enzyme-mediated analysis requires an accurate implementation of several interconnected stages highly regulated in time. Moreover, enzymatic assay systems are expensive and require a strict control over the catalytic activity.

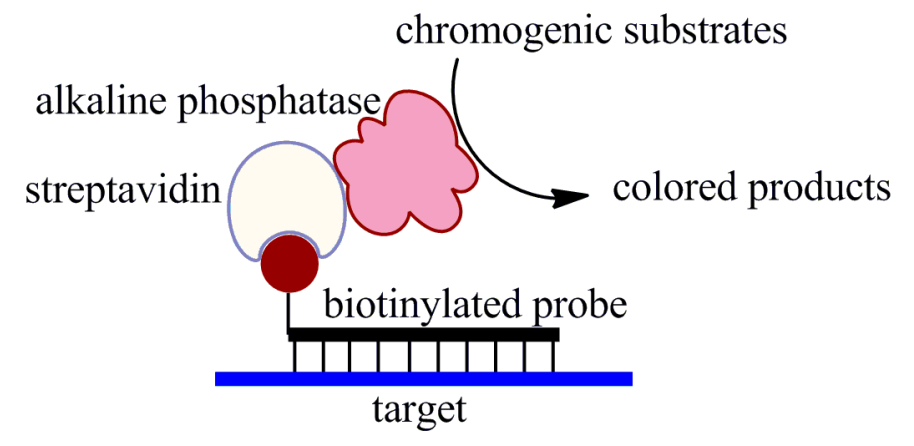

Figure 6. Diagram of colorimetric DNA detection using alkaline phosphatase [40]. 
In addition to the enzymatic systems, colorimetric schemes of DNA detection using gold nanoparticles are extensively developed due to the ability of colloidal gold to change the solution color under the transition from the state of individual particles (red) to the aggregate (blue) [41, 42] (Figure 7). The aggregation process of gold nanoparticles in the solution can be recorded spectrophotometrically or visually. This approach allows the detection of $10^{-9}-10^{-12} \mathrm{M}$ of DNA target [43].
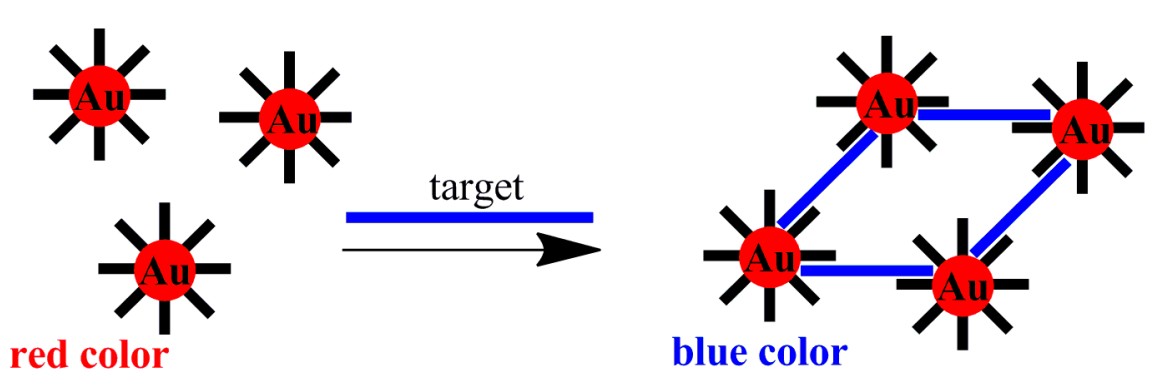

Figure 7. Diagram of a hybridization complex based on the gold nanoparticles aggregation.

If one transfers this approach to the analysis heterophase format, an increase of the signal by further deposition of metallic silver on the gold particles surface is possible, which allows to detect the DNA target in the ultra-low concentrations (up to $10^{-18} \mathrm{M}$ ) [44].

\section{Electrochemical biosensors}

Electrochemical sensors are widely used for analysing the compounds of various classes including the DNA sequences [45]. In the electrochemical sensor, the determined component reacts with the sensitive layer directly on the electrode or in the bulk of the solution near the electrode layer. Because the electrochemical reactions transmit the electric signal, there is no need for the signal conversion device; detection may be performed by the electrochemical analyzer [45]. The electrochemical systems simplicity, efficiency, the possibility of miniaturization and creation of portable devices providing a sensitive and a selective detection of analytes ensure to use such devices in not only research but also practical applications. Depending on the method of measuring the signal, electrochemical sensors can be divided into potentiometric ones measuring the potential of the cell that is proportional to the logarithm of the analyte concentration; voltammetric (amperometric) ones measuring the strength of the current passing through the electrode surface, which is directly proportional to the concentration of the electrochemically active (i.e., capable of oxidation or reduction) analyte; conductometric ones measuring electrical conductivity of the analytical cell which is sensitive to changes in composition of the solution under the chemical reaction implementation or complexation [7].

The current electrochemical approaches to NA detection can be divided into techniques using reporter groups, for example, ferrocene [46], nanoparticles [47], minor groove binding ligands [48], intercalators [49], and not using reporter groups ( 'label-free') [11 ].

Because of their simplicity, the DNA detection methods based on redox reactions taking place directly in the DNA become more widely spread. The quantity of DNA, reduced or oxidized, may indicate the amount of DNA target complexed with the NA probe attached to the surface of the electrode [11]. The most electrochemically active nitrogenous base is a guanine; its oxidation parameters are clearly distinguishable from the oxidation parameters of other bases [50].

The authors of the paper [11] described a DNA detection using a differential pulse voltammetry method based on the oxidation of guanine residues in the sequence of the NA-probe immobilized on an electrode. DNA duplex formation led to prevent oxidation of guanine, and hence, to reduce the magnitude of the recorded signal. To increase sensitivity (up to $2.7 \times 10^{-10} \mathrm{M}$ ) and specificity of the method as probes, the authors used a peptidyl nucleic acid (PNA). PNA is a DNA analogue in which the negatively charged sugar-phosphate backbone is replaced by a pseudopeptide uncharged chain consisting of repeating residues of N-(2-aminoethyl) glycine units linked by amide bonds. Another 
way to improve the detection of such systems can be the usage of the NA-probes, in which the guanine residues are replaced by inosine, preferably binding to cytosine base. In this case, under hybridization assay, the appearance of the guanine oxidation signal will indicate the formation of the complex with the DNA analyte containing the reporter guanine residues.

However, the use of these methods is complicated by considerable background currents in the conditions required for direct DNA oxidation [51]. Moreover, such a nonspecific signal in the assay system may appear due to the DNA nonspecifically adsorbed to the electrode.

In the development of electrochemical sensors for the NA determination, the methods based on the change in the electrical properties of the surface: impedance, admittance, the system capacity are used. Such transducers can detect the processes accompanied by the change in the total number of dissolved ions, their charge and mobility. In studying the dependences of the resistance or conductance on the AC frequency, the admittance or impedance spectra are obtained. The appropriate approach is called the electrochemical impedance spectroscopy (EIS) [7]. The examples of surfaces capable to change the electrochemical properties are polymer films (polythiophene derivatives) [16] (sensitivity of $5 \times 10^{-10} \mathrm{M}$ [52]), silicon nanowires (sensitivity of $10^{-12}-10^{-15} \mathrm{M}$ ) [53].

The leading development line in the field of diagnostic biosensors takes the nanobiosensors based on one-dimensional nanostructures: nanowires, nanotubes and nanofibers [54]. The principle of action for a biosensor based on one-dimensional nanowire as the gate field effect transistor is set up on the effect depending on the flowing through the current transistor from the field on the gate nanowire. The binding of biomolecular marker in the sample with the surface of the sensor element results in a change in its surface potential and, consequently, in an increase in the strength of the current passing through the sensor element, which is fixed by an analog-digital converter [55, 56]. This approach allows one to get the exponential dependence of the conductivity of the silicon nanowires on a charge on its surface, thus, to increase the signal/noise ratio and obtain sensitive detection marker molecules to $10^{-14}-10^{-15} \mathrm{M}$, which corresponds to the best modern analogues. Theoretically, such a detection limit of the sensor system corresponds to the registration of single molecules of analyte. To date, the literature presents works that allow to conduct rapid detection of marker nucleic acid sequences with help of the nanowire biosensor within a few minutes with a sensitivity of $10^{-15} \mathrm{M}$ concentration [57, 58] (Figure 8).

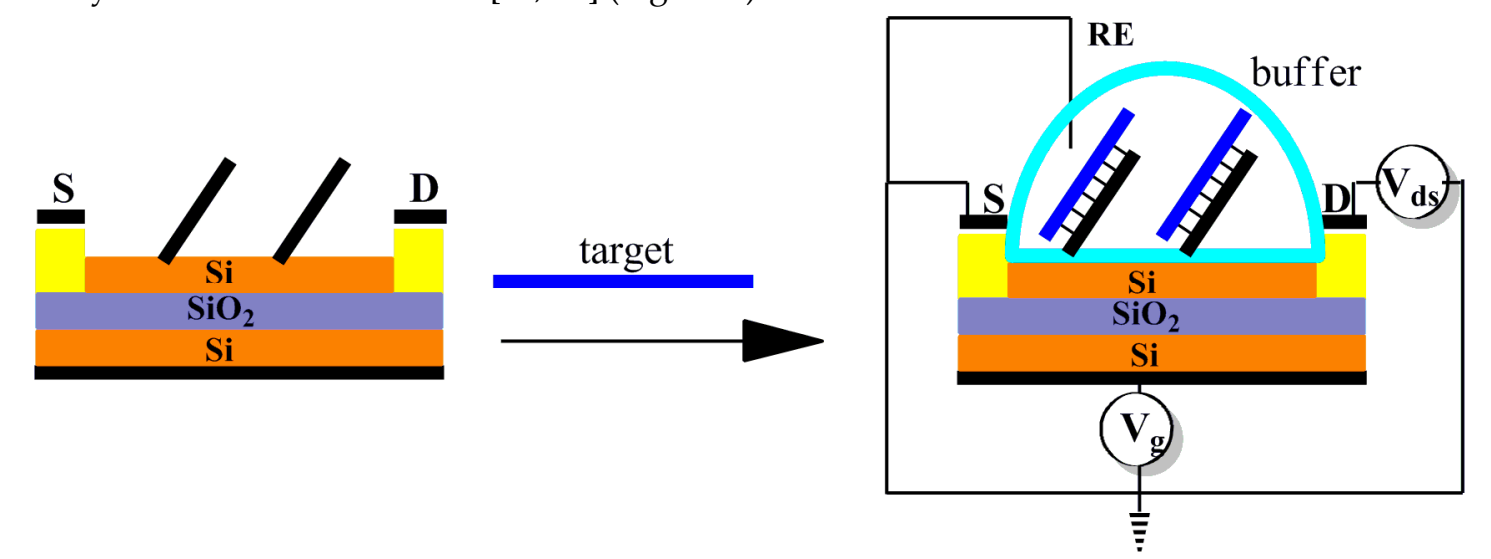

Figure 8. A general scheme of biosensing measurement setup of Si-nanowire sensors [53].

Using as probes, the immobilized on the nanowire surface, uncharged NA analogs such as peptide nucleic acid (PNA), morpholino (MO) or phosphoryl guanidine (PGO) derivatives with heteroduplex formation with the analyte target, leads to increase in sensor sensitivity $[57,59,60]$.

Another approach in the design of electrochemical biosensors is usage of nanotubes or nanochannels formed by biomolecules [61, 62] or inorganic materials [63]. It was shown that displacement of individual ssDNA molecules through the nanopores (radius $1.4 \mathrm{~nm}$ ) formed by $\alpha$-hemolysin (from Staphylococcus aureus) in the lipid membrane can be reliably recorded, analyzing the ion current in an electrical cell [61]. However, biosensors based on the use of biological nanochannels have a number of disadvantages (fixed pore size, the instability of the lipid bilayer under changing the external parameters [62]) that limits the possibility of their application. To solve 
these problems when, one can use nanochannels formed in a stable inorganic materials. For example, in the paper [64] the possibility of selective detection of single-stranded DNA (at a concentration of $10^{-11} \mathrm{M}$ ) is demonstrated as it passes through the silicon membrane with nanochannels of $20 \mathrm{~nm}$ diameter. In this case, the nanochannel surface was modified by the hairpin oligonucleotide probes, which reduced the effective cross-section of channels to 1-2 nm and allowed to reach a reliable change in the electrical conductivity in the cell during the passage of the DNA analyte through the membrane (Figure 9).

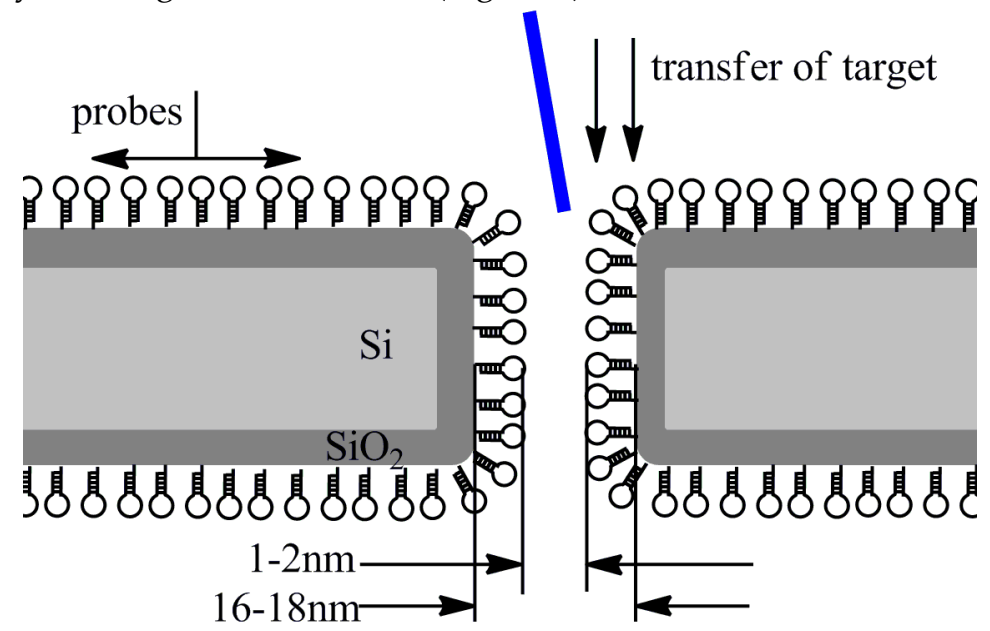

Figure 9. Diagram of the sensor based on a nanochannel with a silicon substrate [64].

The progress in creating the electrochemical biosensors became possible by using diffusion-mobile low molecular weight substances (which are electron carriers) as the oxidizing mediators [65]. The advantages of mediators are reversible redox processes, lower redox potentials and ease of a constant concentration maintenance. As mediators, transition metal cations (ions $\mathrm{Fe}^{3+}$, $\mathrm{Ru}^{3+}$ and $\mathrm{Os}^{3+}$ ) and their complexes (hexacyanoferrate $\left[\mathrm{Fe}(\mathrm{CN})_{6}\right]^{3-}$ ), ferrocene, a number of organic dyes (e.g. methylene blue) are commonly used [45].

An example of the biosensor device for DNA indirect detection via polypyridine complexes $\mathrm{Ru}(\mathrm{II})$ and Os(II) is presented in [66] (Figure 10). In this case, the presence of the DNA analyte, i.e. guanine residues in its structure, ensures the implementation of the catalytic cycle $\mathrm{Ru}(\mathrm{bpy}) 3^{2^{2+}} \rightarrow$ $\mathrm{Ru}(\mathrm{bpy}) 3^{3^{+}} \rightarrow \mathrm{Ru}(\mathrm{bpy}) 3^{3^{2+}}$ (bpy $=2,2^{2}$-bipyridine. The absence of guanine as part of the NA-probe leads to a single oxidation of $\mathrm{Ru}(\mathrm{bpy}) 3^{2+}$, while the full cycle only occurs in the presence of guanine.
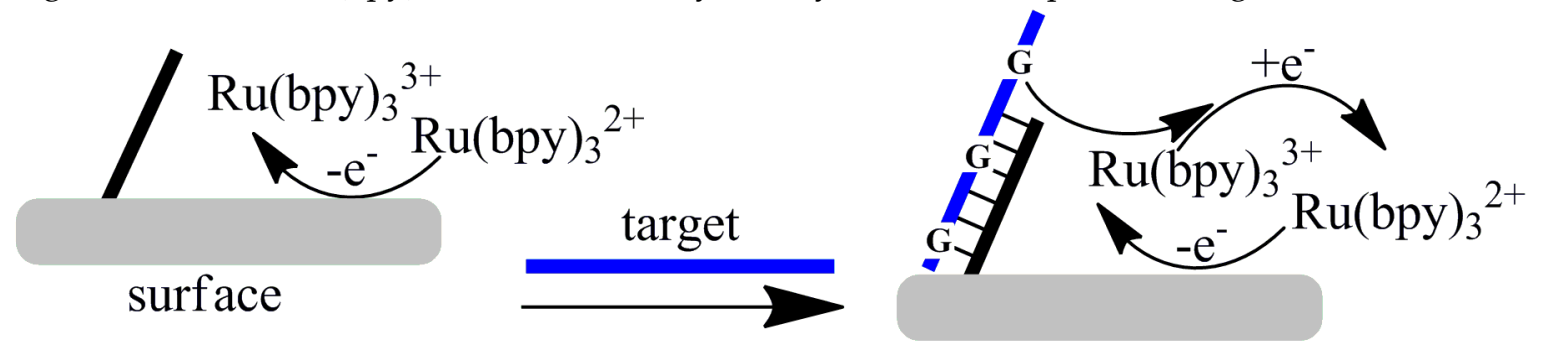

Figure 10. Diagram of the DNA sensor based on the oxidation of guanine bases of DNA target [66].

This principle was applied to detect DNA on the unmodified electrode made of indium tin oxide alloy [66]. The sensitivity of the method reaches $5.5 \times 10^{-11} \mathrm{M}$ of the DNA target, and detection of various DNA sequences may be implemented in parallel analysis mode [67].

For the development of electrochemical methods to analyze the DNA sequences, the following strategies are successfully applying as reporters redox molecules capable to noncovalently bind to DNA duplexes, e.g., minor groove binding ligands such as Hoechst 33258 [68] or intercalators, e.g., methylene blue [49], doxorubicin [69], ethidium bromide, [70], as well as antibiotics and other dyes. Using this approach, the detection limit of the analyzed DNA sequence is $\sim 10^{-11} \mathrm{M}$ [48]. (Figure 11). 


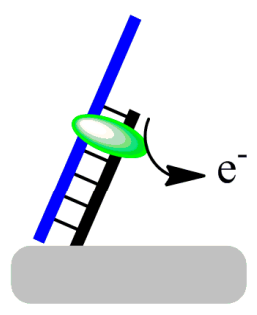

$\mathrm{a}$

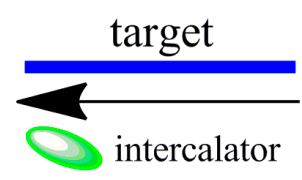

intercalator

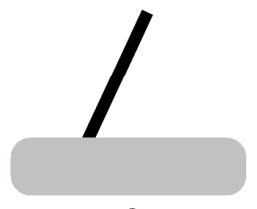

surface

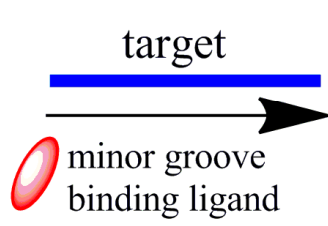

binding ligand

Figure 11. The electrochemical DNA sensors based on redox-active hybridization indicators using intercalators (a) or minor groove binding ligands (b).

In the electrochemical analysis, the techniques using reporter groups (as redox active compounds, particularly, ferrocene and derivatives thereof) are popular [71]. Due to its low redox potential and stability of reduced and oxidized forms, ferrocene is used as the reporter group under the DNA assay. Most often, ferrocene composed of modified nucleoside or oligonucleotide is introduced into an electrochemical detection system under enzymatic elongation of DNA sequences. In this system, DNA processing enzymes cannot only participate in the product forming, but provide additional selectivity and analysis. In the paper [46], on proposes a strategy for detection of point mutations based on the oxidation of the ferrocene label, which is in close proximity to the surface of the electrode formed after duplex ligation and subsequent DNA removal (Figure 12).

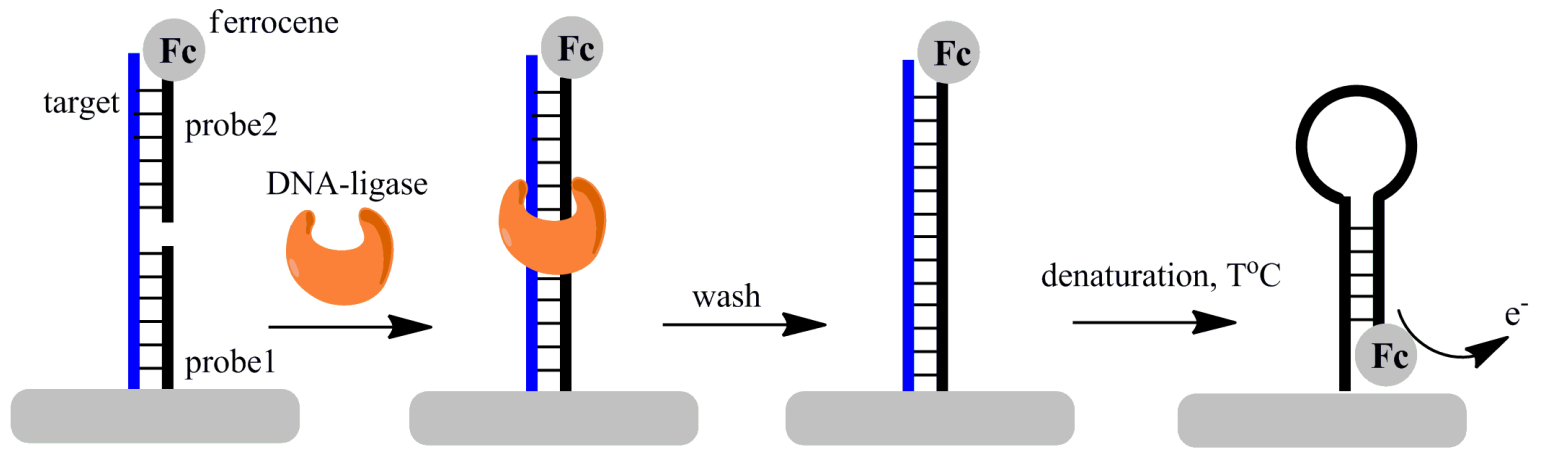

Figure 12. Diagram of operation for electrochemical DNA sensors based on ferrocene oxidation using DNA ligase [46].

The sensitivity of the analyzed DNA detection by stripping voltammetry method was $\sim 10^{-12} \mathrm{M}$.

The use of enzymes in the electrochemical DNA analysis has become widespread due to their ability to convert single cases of hybridization complex forming to detections of a larger number of signaling molecules formed by the enzyme, which leads to a significant enhancement of the recorded signal. Typically, in electrochemical sensors, horseradish peroxidase [72], glucose oxidase [73], esterase [74], and other enzymes relatively stable, inexpensive and having a high catalytic activity are used. Creation of such sensors can be possible if one picks up a product of the enzymatic reaction, which is electrochemically active, i.e., it can quickly and, preferably, reversibly oxidized or reduced at an electrode when applied to his respective capacities. An example of electrochemical NA detection using an enzyme-esterase is a selective microRNA detection composed of a signal quaternary hybridization complex formed on the electrode surface (Figure 13). In the formation of a hybridization complex, enzyme as part of an oligonucleotide conjugate is near the electrode and converts the p-aminophenylbutyrate substrates into a p-aminophenol, which in turn is oxidized at the electrode and it provides a reliably detectable electrochemical signal. In the absence of microRNA, hybridization complex near the electrode is not stable, and the analytic signal is not observed. The proposed prototype of biosensor makes it possible to detect microRNAs with a detection limit of $\sim 10^{-12} \mathrm{M}$. 


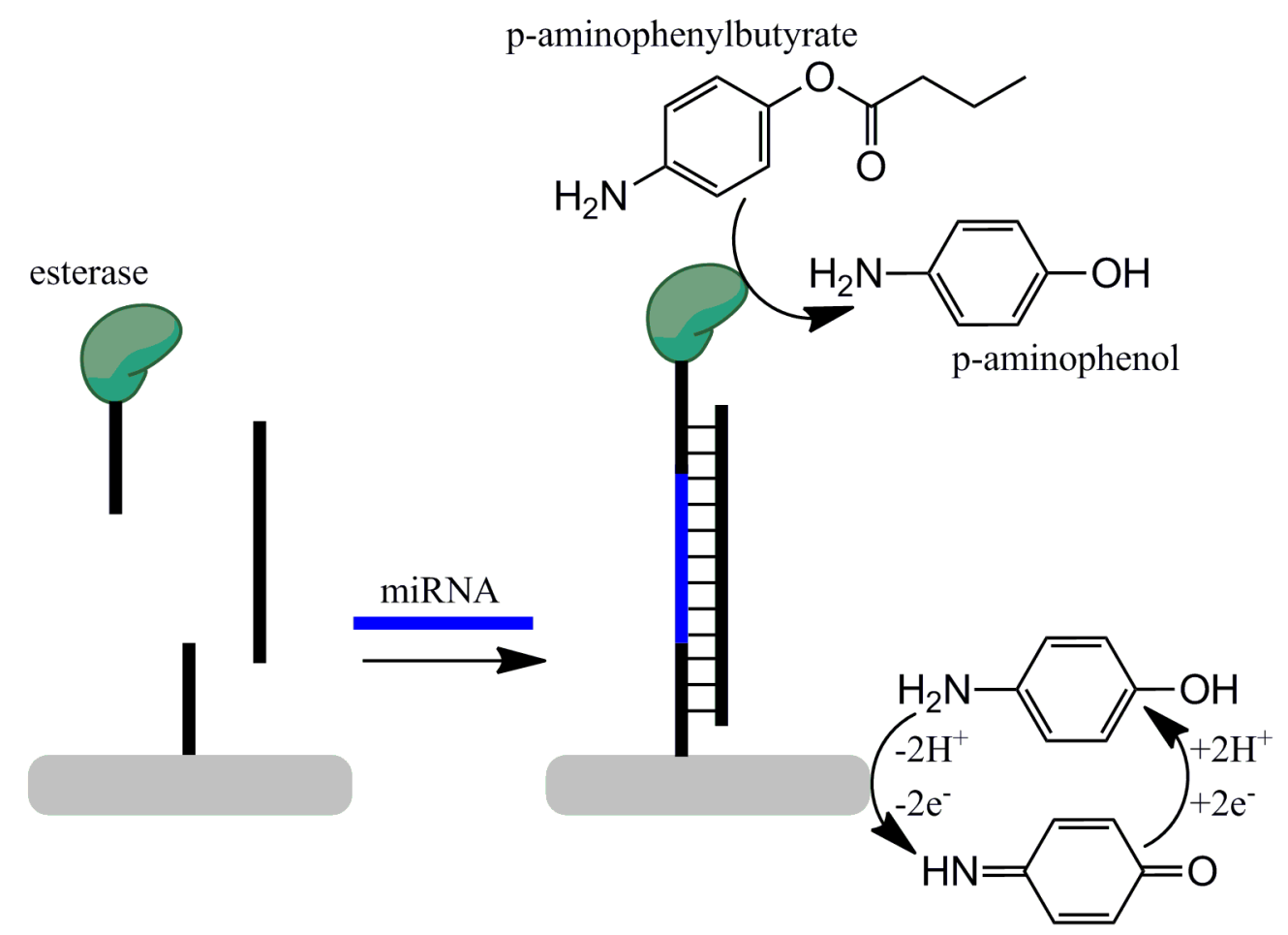

Figure 13. Diagram of the biosensor device using an enzymatic system [74].

Another example of successful using the enzyme systems in electrochemical biosensors is the approach to the identification of DNA cytomegalovirus developed under application of biotinylated oligonucleotide probes and streptavidin conjugate of horseradish peroxidase. The enzyme catalyzes the conversion of o-phenylenediamine into 2,2'-diaminobenzene that as an electrochemically active product [75] can be detected by differential pulse voltammetry. In this system, the sensitivity of the analyzed DNA detection is $\sim 10^{-16} \mathrm{M}$.

\section{Micromechanical (piezoelectric) sensors}

Piezoelectricity is a phenomenon of dielectric polarization under the influence of mechanical stresses (a direct piezoelectric effect) as well as of mechanical deformation under the influence of an electric field (an inverse piezoelectric effect). Direct and inverse piezoelectric effects are observed in the same crystals, i.e., piezoelectrics. In the sensors, there are used both natural (quartz, tourmaline) and ceramic piezoelectrics (barium titanate, lead titanate, etc.); also some polymeric materials (PVDF) have piezoelectric properties. Each crystal has its own resonant oscillation frequency, which may depend on its environment. A value of the resonant frequency depends on the mass of the crystal and the material adsorbed thereon that can be measured with exceptionally high accuracy [7].

At present, systems and devices based on the so-called quartz crystal microbalance are widely used [7]. The analyzer operates based on microbalance weighing method in relation to the detecting component sorbed by a sensitive layer. However, when using this system, the problems associated with a lack of sensitivity and high noise levels were noted. There is a modification of the quartz crystal microbalance with a special signal amplification circuit called electrochemical quartz crystal microbalance. The device detects the change in the electrode mass, which occurs as a result of the substance adsorption or desorption in the surface monolayer; electroactive substances deposition or dissolution throughout the redox processes. By incorporating oligonucleotide probes as part of the layer the coats the piezoelectric crystal, substantially higher sensitivity sensors can be achieved [17]. There are known the electrochemical quartz crystal microbalance biosensors to detect the NA duplexes containing nanoparticles (gold [17], $\mathrm{Fe}_{3} \mathrm{O}_{4}$ [76]), liposomes [77]) or not containing the reporter groups [16]. The electrochemical quartz crystal microbalance signal amplification can be achieved using either enzymatic labels already described above (conjugate avidin-alkaline 
phosphatase and 5-bromo-4-chloro-3-indolyl phosphate [78] with a sensitivity limit of $\sim 3 \times 10^{-16} \mathrm{M}$ ) or tags based on liposomes and dendrimer structures (Figure 14) [77] (the sensitivity limit to DNA analyte $5 \times 10^{-12} \mathrm{M}$ and $10^{-13} \mathrm{M}$ respectively), or gold nanoparticles, for example, modified ones like a random set of tetranucleotides called by the authors as 'nanoamplikons' (Figure 15) [17]. Detection limit for single-stranded genomic DNA with application of nanoamplikons was $1.7 \times 10^{-19} \mathrm{M}$, that is the highest sensitivity level among the analytical methods discussed above.

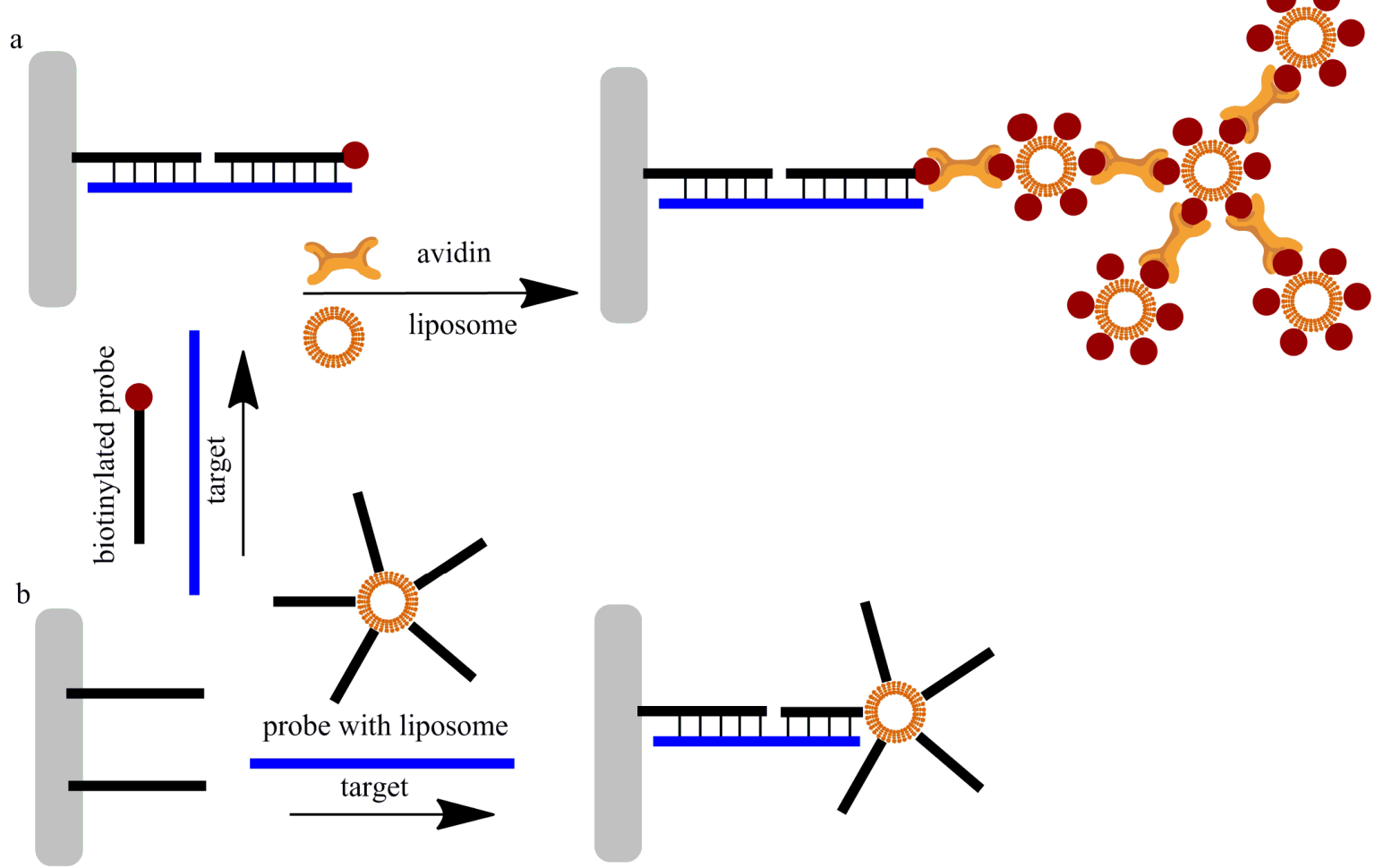

Figure 14. Diagram of NA detection using electrochemical quartz crystal microbalance with liposomes [77].

Oligonucleotide probe

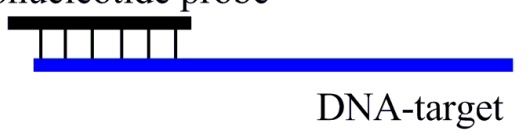

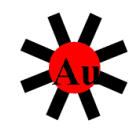
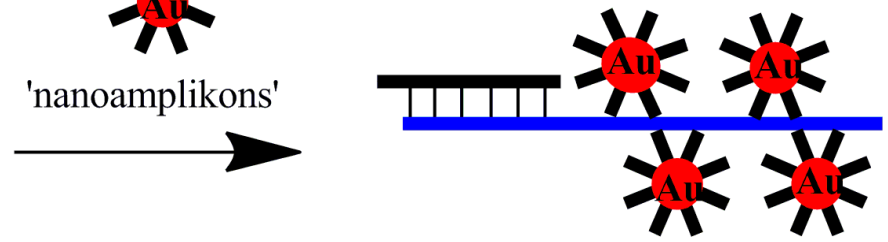

Figure 15. Diagram for DNA detecting using electrochemical quartz crystal microbalance with 'nanoamplicons' [17].

In addition, the authors of the paper [79] showed that by using MutS protein with the electrochemical quartz crystal microbalance biosensor one is able to distinguish committed DNA duplexes and duplexes with non-complementary areas. Detection redistribution for DNA duplex containing discrepancy ( $\mathrm{T} / \mathrm{G}$ mismatch or nucleotide looping out) amounted to $10^{-9} \mathrm{M}$.

Another type of sensor devices allowing to carry out the registration of small masses is microscopic resonance systems - microbalance-based cantilevers for atomic force microscopy (AFM), which, according to the estimates, will achieve the threshold of sensitivity down to single molecules $[20,80]$. The cantilever for AFM typically is a probe in the form of a needle grown from a strong inorganic material at the end of the foldaway beam. The cantilevers can be effectively used to study chemical processes that occur upon binding of specific molecules on their surface that allows one to create highly sensitive biosensors on their basis that can detect, for example, the NA-analyte without the use of reporter groups [81-86]. The general principle of operation of the sensor, in this case, can be represented as follows. Because of the interaction of the modified surface of the cantilever and the 
detectable substance, a difference of surface tension forces on opposite sides of the cantilever occurs, which bends under the action of the cantilever. Such a bending is recorded using an optical laser system [80]. Often, the sensor device uses more than one cantilever, i.e., set of cantilevers tacked on a common base [80, 87]. It demonstrated that the ssDNA registration using this type of sensors with two cantilever allows revealing the analyte concentration to $10^{-11} \mathrm{M}$ [88] (Figure 16).
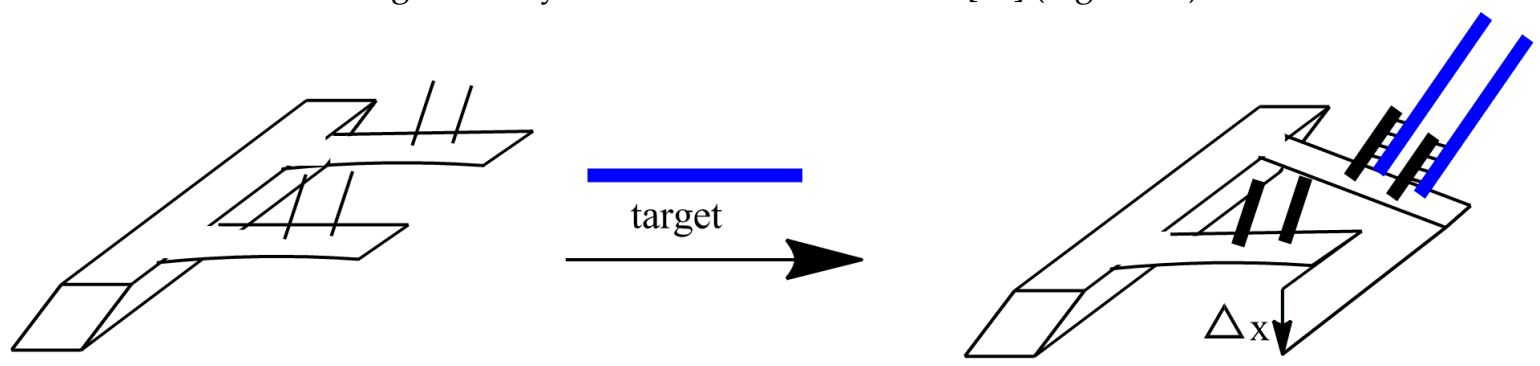

Figure 16. The principle of DNA sensor based on cantilever [88].

Another promising principle for creating a micromechanical sensor is an approach that makes it possible to determine the bond braking strength due without external electromagnetic action on the object, and therefore it is of great value for studying the biological objects, such as nucleic acids [89, 90]. The technique is based on the use of quartz crystal unit as a sensor that also plays an active role with respect to the particle fastened off on the surface thereof. Harmonic voltage U0 of the continuously variable amplitude (from 0 to 10 volts for a time of $30-120$ seconds) with the quartz resonator frequency $(\mathrm{F}=14 \mathrm{MHz})$ is supplied from the generator. By increasing the voltage, the amplitude of the shear waves' surface of the quartz resonator increases, and the object is detached from the attachment surface. In addition, this produces an acoustic signal, which is recorded by the same quartz.

Separation of DNA molecules from the sensor surface occurs due to a fluid velocity gradient obtained upon harmonic oscillations of the quartz surface. Since measurements are made near the resonance region of the quartz resonator, any violation of the coherent oscillation system (separation of macromolecules from the surface) lead to significant distortions. This is determined by the high sensitivity and the method's simplicity. Besides, measuring the bond rupture forces is held not with a single molecule as in the case of the use of atomic force microscopy but with the ensemble.

\section{Conclusions}

Thus, the main approaches to the analysis of nucleic acids and the construction of NA-based biosensensing systems ensuring rapid, high-avidity and sensitive detection of molecules analyzed are presented. It should be noted that all the above mentioned approaches are applied not only under the analysis of nucleic acids driven by the NA ability to form complexes with complementary sequences, but also under the analysis of other molecules ensuring the formation of a specific complex. The devices for biosensing ensure with high sensitivity and specificity to identify biomolecules that is an important scientific and practical problem for the day. Every day, technologies are improved; new approaches to the development of biosensensing devices making it possible to quick and accurately obtain the information about the targeted molecular markers are developed.

Acknowledgments: This study was supported by the Ministry of Education and Science of the Russian Federation (Agreement No. 14.607.21.0125 from 27.10.2015). Unique identifier of the project RFMEFI60715X0125.

Conflicts of Interest: The founding sponsors had no role in the design of the study; in the collection, analyses, or interpretation of data; in the writing of the manuscript, and in the decision to publish the results. 


\section{References}

1. Vo-Dinh T., Cullum B. Biosensors and biochips: advances in biological and medical diagnostics // J. Anal. Chem. 2000. V. 366. P. 540-551.

2. Monk D.J., Walt D.R. Optical fiber-based biosensors // Anal. Bioanal. Chem. 2004. V. 379. P. 931-945.

3. Chambers J.P., Arulanandam B.P., Matta L.L., Weis A., Valdes J.J. Biosensor recognition elements // Curr. Issues Mol. Biol. 2008. V. 10. P. 1-12.

4. Yogeswaran U. and Chen S.-M. A Review on the Electrochemical Sensors and Biosensors // Composed of Nanowires as Sensing Material. Sensors 2008. V. 8. P. 290-313.

5. Diehl F., Grahlmann, Beier M., Hoheisel J.D. Manufacturing DNA microarrays of high spot homogeneity and reduced background signal // Nucleic Acids Res. 2001. V. 29. e38.

6. Wilson D., Nock S. Recent developments in protein microarray technology // Angew. Chem. Int. End. 2003. V. 42. P. 494-500.

7. Eggins B.R. Chemical Sensors and Biosensors. Series Editor: David J. Ando. John Wiley \& Sons, Inc. West Sussex, UK. 2002. ISBN: 978-0-471-89914-3.

8. Mascini M., Palchetti I., Marrazza G. DNA electrochemical biosensors // J. Anal. Chem. 2001. V. 369. P. $15-22$.

9. Wang J. Electrochemical nucleic acid biosensors // Analytica Chimica Acta. 2002. V. 469. P. 63-71.

10. Zhang Y., Zhang K., Ma H. Electrochemical DNA biosensors based on gold nanoparticles / cysteamine / poly(glutamic acid) modified electrode // Am. J. Biomed. Sci. 2009. V. 1. P. 115-125.

11. Kerman K., Ozkan D., Kara P., Erdem A., Meric B., Nielsen P. E., Ozsoz M. Label-free bioelectronic detection of point mutation by using peptide nucleic acid probes // Electroanalysis. 2003. V. 15. P. 667-670.

12. Ha T. Single-molecule fluorescence methods for the study of nucleic acids // Curr. Opin. Struct. Biol. 2001. V. 11. P. 287-292.

13. Kricka L.J., Nucleic acid detection technologies - labels, strategies, and formats // Clin. Chem. 1999. V. 45. P. 453-458.

14. Vo-Dinh T., Alarie J.P., Isola N., Landis D., Wintenberg A.L., Ericson M.N. DNA biochip using a phototransistor integrated circuit // Anal. Chem. 1999. V. 71. P. 358-363.

15. Homola J., Vaisocherova H., Dostalek J., Piliarik M. Multi-analyte surface plasmon resonance biosensing // Methods. 2005. V. 37. P. 26-29.

16. Gautier C., Cougnon C., Pilard J.F., Casse N.J. Label-free detection of DNA hybridization based on EIS investigation of conducting properties of functionalized polythiophene matrix // Electroanal. Chem. 2006. V. 587. P. 276-280.

17. Mo Z.H., Wei X.L. Toward hybridization assays without PCR using universal nanoamplicons // Anal. Bioanal. Chem. 2006. V. 386. P. 2219-2223.

18. Hansen K.M., Thundat T. Microcantilever biosensors // Methods. 2005. V. 37. P. 57-64.

19. Xu D.K., Ma L.R., Liu Y.Q., Jiang Z.H., Liu Z.H. Development of chemiluminescent biosensing of nucleic acids based on oligonucleotide-immobilized gold surfaces // Analyst. 1999. V. 124. P. 533-537.

20. He L., Musick M.D., Nicewarner S.R., et al. Colloidal Au-enhanced surface plasmon resonance for ultrasensitive detection of DNA hybridization // J. Am. Chem. Soc. 2000. V. 122. P. 9071-9077.

21. Cardullo R.A., Agrawal S., Flores C., Zamecnik P.C., Wolf D.E. Detection of nucleic acid hyridization by nonradiactive fluorescence resonanse energy transfer // Proc. Natl. Acad. Sci. 1988. V. 85. P. 8790-8794.

22. Giesendorf B., Vet J., Tyagi S., Mensink E., Trijbels F., Blom H.J. Molecular beacons: a new approach for semiautomated mutation analysis // Clin. Chem. 1998. V. 44. P. 482-486.

23. Strohsahl C.M., Du H., Miller B.L., Krauss T.D. Towards single-spot multianalyte molecular beacon biosensors // Talanta. 2005. V. 67. P. 479-583.

24. Zhao X., Tapec-Dytioco R., Tan W. Ultrasensitive DNA detection using highly fluorescent bioconjugated nanoparticles // J. Am. Chem. Soc. 2003. V. 125. P. 114-118.

25. Somers R. C., Bawendi M. G., Nocera D. G. Cd-Se nanocrystal based chem-/bio- sensors // Chem. Soc. Rev. 2007. V. 36. P. 579-583.

26. Fleischmann M. Raman spectra of pyridine adsorbed at a silver electrode // Chem. Phys. 1974. V. 26. P. 163-166.

27. Yonzon, C.R., Stuart, D.A., Zhang, X., McFarland, A.D., Haynes, C.L. Towards advanced chemical and biological nanosensors // Talanta. 2005. V.67. P. 438-448. 
28. Cao Y.W., Jin R.C., Mirkin C.A. Nanoparticles with Raman spectroscopic fingerprints for DNA and RNA detection. // Science. 2002. V. 297. P. 1536-1540.

29. Vo-Dinh T., Houck K., Stokes D.L. Surface-enhanced Raman gene probes // Anal. Chem. 1994. V. 66. P. 3379-3383.

30. Wabuyele M.B., Vo-Dinh T. Detection of human immunodeficiency virus type 1 DNA sequence using plasmonics nanoprobes // Anal. Chem. 2005. V. 77. P. 7810-7815.

31. Kukanskis K., Elkind J., Melendez J., Murphy T., Miller G., Garner H. Detection of DNA hybridization using the TISPR-1 surface plasmon resonance biosensor // Anal. Biochem. 1997. V. 274. P. 7-17.

32. Yao X., Li X., Toledo F., Zurita-Lopez C., Gutova M., Momand J., Zhou F. M. Sub-attomole oligonucleotide and p53 cDNA determinations via a high-resolution surface plasmon resonance combined with oligonucleotide-capped gold nanoparticle signal amplification // Anal. Biochem. 2006. V. 354. P. 220-224.

33. Marchand G., Broyer P., Lanet V., Delattre C., Foucault F., Menou L., Calvas B., Mallard F., Opto-electronic DNA chip-based integrated card for clinical diagnostics // Biomed. Microdevices. 2008. V. 10. P. 35-45.

34. Marquette C.A., Thomas D., Degiuli A., Blum L.J. Design of luminescent biochips based on enzyme, antibody, or DNA composite layers // Anal. Bioanal. Chem. 2003. V. 377. P. 922-926.

35. Marquette C.A., Blum L.J. Conducting elastomer surface texturing: a path to electrode spotting Application to the biochip production // Biosens. Bioelectron. 2004. V. 20. P. 197-202.

36. Borisova, V.V., Pyshnaya, I.A., Pyshnyi, D.V., Frank, L.A. A highly sensitive and rapid method for the detection of DNA fragments using the photoprotein obelin as a reporter // Russian J. Bioorgan. Chem. 2008. V. 34. P. 709-715.

37. Zerefos P., Ioannou P., Traeger-Synodinos J., Dimissianos G., Kanavakis E., Christopoulos T. // Photoprotein aequorin as a novel reporter for SNP genotyping by primer extension-application to the variants of mannose-binding lectin gene //Hum. Mutat. 2006. V. 27. P. 279-285.

38. Michelini E., Guardigli M., Magliulo M., Mirasoli M., Roda A., Simoni P., Baraldini M. //Bioluminescent biosensors based on genetically engineered living cells in environmental and food analysis// Anal. Lett. 2006. V. 39. P. 1503-1515.

39. . Alloush H., Anderson E., Martin A., Ruddock M., Angell J., Hill Ph., Mehta P., Smith M., Smith J., Salisbury V. // A bioluminescent microbial biosensor for in vitro pretreatment assessment of cytarabine efficacy in leukemia // Clin. Chem. 2010. V. 56. P. 1862-1870.

40. Pyshnyi D.V., Skobeltsyna L.M., Gushchina E.N., Pyshnaya I.A., Shishkina I.G., Dymshits G.M., Zarytova, V.F., Ivanova E.M. Detection of single-base substitutions in amplified fragments via ligation of a tandem of short oligonucleotides in solution and on a solid carrier // Molekulyarnaya Biologiya. 2000. V. P. 984-997.

41. Baptista P., Doria G., Henriques D., Pereira E., Franco R. Colorimetric detection of eukaryotic gene expression with DNA-derivatized gold nanoparticles // J. Biotechnol. 2005. V. 119. P. 111-117.

42. Elghanian R., Storhoff J.J., Mucic R.C., Letsinger R.L., Mirkin C.A. Selective colorimetric detection of polynucleotides based on the distance-dependent optical properties of gold nanoparticles // Science. 1997. V. 277. P. 1078-1081.

43. Thaxton C.S., Georganopoulou D.G., Mirkin C.A. Gold nanoparticle probes for the detection of nucleic acid targets // Clin. Chim. Acta. 2006. V. 363. P. 120-126.

44. Taton T.A., Mirkin C.A., Letsinger R.L. Scanometric DNA array detection with nanoparticle probes // Science. 2000. V. 289. P. 1757-1760.

45. Drummond T.G., Hill M.G., Barton J.K. Electrochemical DNA sensors // Nat. Biotechnol. 2003. V. 21. P. 1192-1199.

46. Mearns F.J., Wong E.L.S., Short K., Hibbert D.B., Gooding J.J. DNA biosensor concepts based on a change in the DNA persistence length upon hybridization // Electroanalysis. 2006. V. 18. P. 1971-1981.

47. Merkoci A., Aldavert M., Marin S. New materials for electrochemical sensing V: Nanoparticles for DNA labeling // Trends Anal. Chem. 2005. V. 24. P. 341-345.

48. Niu S.Y., Zhang S.S., Wang L., Li X.M. Hybridization biosensor using di(1,10-phenanthroline) (imidazo[f]1,10-phenanthroline)cobalt(II) as electrochemical indicator for detection of human immunodeficiency virus DNA // J. Electroanal. Chem. 2006. V. 597. P. 111-118. 
49. Lin X.-H., Wu P., Chen W., Zhang Y.-F., Xia X.-H. Electrochemical DNA biosensor for the detection of short DNA species of Chronic Myelogenous Leukemia by using methylene blue // Talanta. 2007. V. 72. P. 468-473.

50. Wang J., Rivas G., Fernandes J.R., Paz J.L.L., Jiang M., Waymire R. Indicator-free electrochemical DNA hybridization biosensor // Anal. Chim. Acta. 1998. V. 375. P. 197-201.

51. Wang J., Kawde A.N., Erdem A., Salazar M. Magnetic bead-based label-free electrochemical detection of DNA hybridization // Analyst. 2001. V. 126. P. 2020-2024.

52. Fu Y., Yuan R., Chai Y., Zhou L., Zhang Y. Coupling of a reagentless electrochemical DNA biosensor with conducting polymer film and nanocomposite as matrices for the detection of the HIV DNA sequences // Anal. Lett. 2006. V. 39. P. 467-482.

53. Zhang G.J., Ning Y. Silicon nanowire biosensor and its applications in disease diagnostics: a review. Anal. Chim. Acta. 2012. V. 749. P. 1-15.

54. Bellan L.M., Wu D. and Langer R.S. Current trends in nanobiosensor technology. WIREs Nanomed Nanobiotechnol. 2011. V. 3. P. 229-246. DOI: 10.1002/wnan.136.

55. Zheng G., Patolsky F., Cui Y., Wang W.U., Lieber C.M. Multiplexed electrical detection of cancer markers with nanowire sensor arrays // Nat. Biotechnol. 2005. V. 23. P. 1294-1301.

56. Naumova O.V, Fomin B.I., Nasimov D.A. et.al. SOI nanowires as sensors for charge detection. Semicond. Sci. Technol. 2010. V. 25. P. 055004.

57. Dmitrienko E., Naumova O., Fomin B., Kupryushkin M., Volkova A., Amirkhanov N., Semenov D., Pyshnaya I., Pyshnyi D. Surface modification of SOI-FET sensors for label-free and specific detection of short RNA analyte // Nanomedicine. 2016. V. 11. P. 2073-2082.

58. Zhang G.-J., Chua J.H.,. Chee R.-E, Agarwal A., Wong S.M., Buddharaju K.D., Balasubramanian N. Highly sensitive measurements of PNA-DNA hybridization using oxide-etched silicon nanowire biosensors // Biosens. Bioelectron. 2008. V. 23. P. 1701-1707.

59. Zhang G-J, Luo Z.H., Huang M.J. et al. Morpholino-functionalized silicon nanowire biosensor for sequence-specific label-free detection of DNA. // Biosens. Bioelectron. 2010. V. 25. P. 2447-2453.

60. Gao Z., Agarwal A., Trigg A., Singh N., Fang C., Tung C.-H., Fan Y., Buddharaju K. D., Kong J. Silicon nanowire arrays for label-free detection of DNA // Anal. Chem. 2007. V. 79. P. 3291-3297.

61. Kasianowicz J., Brandin E., Branton D., Deamer D.W. Characterization of individual polynucleotide molecules using a membrane channel // Proc. Natl Acad. Sci. 1996. V. 93. P. 770-773.

62. Nakane J., Wiggin M., Marziali A. A nanosensor for transmembrane capture and identification of single nucleic acid molecules // Biophysic. J. 2004. V. 87. P. 615-621.

63. Li S., Li J., Wang K., Wang C., Xu J., Chen H., Xia X., Huo Q. // A nanochannel array-based electrochemical device for quantitative label-free DNA analysis // ACS Nano. 2010. V. 4. P. 6417-6424.

64. Iqbal S.M., Akin D., Bashir R. Solid-state nanopore channels with DNA selectivity // Nat. Nanotechnol. 2007. V. 2. P. 243-248.

65. Evtugyn G., Porfireva A., Stepanova V., Budnikov H. Electrochemical Biosensors Based on Native DNA and Nanosized Mediator for the Detection of Anthracycline Preparations // Electroanalysis. 2015. V. 27. P. 629 - 637. DOI: 10.1002/elan.201400564

66. Napier M. E., Loomis C. R., Sistare M. F., Kim J., Eckhardt A. E., Thorp H. H. Probing biomolecule recognition with electron transfer: electrochemical sensors for DNA hybridization // Bioconjugate Chem. 1997. V. 8. P. 906-909.

67. Popovich N. D. Mediated electrochemical detection of nucleic acids for drug discovery and clinical diagnostics // IVD Technol. 2001. V. 7. P. 36-40.

68. Ito K., Hashimoto K., Ishimori Y. Quantitative analysis for solid-phase hybridization reaction and binding reaction of DNA binder to hybrids using a quartz crystal microbalance // Anal. Chim. Acta. 1996. V. 327. P. 29-35.

69. Patolsky F., Katz E., Willner I. Amplified DNA detection by electrogenerated biochemiluminescence and by the catalyzed precipitation of an insoluble product on electrodes in the presence of the doxorubicin intercalator // Angew. Chem., Int. Ed. 2002. V. 41. P. 3398-3402.

70. Liu S.H., Ye J.N., He P.G., Fang Y.H. Voltammetric determination of sequence-specific DNA by electroactive intercalator on graphite electrode // Anal. Chim. Acta. 1996. V. 335. P. 239-243.

71. Wlassoff W.A., King G.C. Ferrocene conjugates of dUTP for enzymatic redox labelling of DNA // Nucleic Acids Res. 2002.V. 30. e58. 
72. Azek F., Grossiord C., Joannes M., Limoges B., Brossier P. Hybridization assay at a disposable electrochemical biosensor for the attomole detection of amplified human cytomegalovirus DNA // Anal. Biochem. 2000. V. 284. P. 107-111.

73. Xie H., Zhang C. Y., Gao Z. Q. Amperometric detection of nucleic acid at femtomolar levels with a nucleic acid/electrochemical activator bilayer on gold electrode // Anal. Chem. 2004. V. 76. P. 1611-1617.

74. Sprinzl P. Electrochemical detection of micro RNA via gap hybridization assay // Anal. Chem. V. 82. P. 4434-4440.

75. Erdem A., Pividori M. I., Lermo A., Bonanni A., Valle M., Alegret S. Genomagnetic assay based on label-free electrochemical detection using magneto-composite electrodes // Sens. Actuators. B. 2006. V. 114. P. 591-596.

76. Mao X.L., Yang L.J., Su X.L.. Li Y.B. A nanoparticle amplification based quartz crystal microbalance DNA sensor for detection of Escherichia coli O157:H7 // Biosens. Bioelectron. 2006. V. 21. P. 1178-1181.

77. Patolsky F., Lichtenstein A., Willner I. Amplified microgravimetric quartz-crystal-microbalance assay of DNA using oligonucleotide-functionalized liposomes or biotinylated liposomes // J. Am. Chem. Soc. 2000. V. 122. P. 418-419.

78. Willner I., Patolsky F., Weizmann Y., Willner B. Amplified detection of single-base mismatches in DNA using microgravimetric quartz-crystal-microbalance transduction // Talanta. 2002. V. 56. P. 847-851.

79. Su X., Robelek R., Wu Y., Wang G., Knoll W. Detection of point mutation and insertion mutations in DNA using a quartz crystal microbalance and MutS, a mismatch binding protein // Anal. Chem. 2004. V. 76. P. 489-494.

80. Lang H.P., Hegner M., Gerber C. Cantilever array sensors // Mater. Tod. 2005. V. 8. P. 30-36.

81. Ziegler C. Cantilever-based biosensors. Anal. Bioanal. Chem. 2004. V. 379. P. 946-959.

82. Lavrik N.V., Sepaniak M.J., Datskos P.G. Cantilever transducers as a platform for chemical and biological sensors // Rev. Sci. Instrum. 2004. V. 75. P. 22-29.

83. Lechugaa L.M., Tamayo J, Alvarez M, Carrascosa L.G., Yufera A, Dold'an R, Peralias E, Rueda A, Plaza J.A., Zinoviev $\mathrm{K}$, et al. A highly sensitive microsystem based on nanomechanical biosensors for genomics applications // Sens. Actuat B: Chem. 2006. V. 118. P. 2-10.

84. Zhang J, Lang H.P., Huber F., Bietsch A., Grange W., Certa U., Mckendry R., Guntherodt H., Hegner M., Gerber C. Rapid and label-free nanomechanical detection of biomarker transcripts in human RNA // Nat. Nanotech. 2006. V. 1. P. 214-220.

85. Backmann N., Zahnd C., Huber F., Bietsch A., Pluckthun A., Lang H.P., Guntherodt H.J., Hegner M., Gerber C. A label-free immunosensor array using single-chain antibody fragments // Proc. Natl. Acad. Sci. 2005. V. 102. P. 14587-14592.

86. Fritz J. Cantilever biosensors // Analyst. 2008. V. 133. P. 855-863.

87. Calleja M., Nordstrom M., Alvarez M., Tamayo J., Lechuga L.M., Boisen A. Highly sensitive polymer-based cantilever-sensors for DNA detection // Ultramicroscopy. 2005. V. 105. P. 215-222.

88. Fritz J., Baller M.K., Lang H.P., Rothuizen H., Vettiger P., Meyer E., Guntherodt H.J., Gerber C., Gimzewski J.K. Translating biomolecular recognition into nanomechanics // Science. 2000. V. 288. P. 316-320.

89. Dultsev F.N., Kolosovsky E.A., Cooper M.A., Lomzov A.A., Pyshnyi D.V. QCM-Based Rapid Analysis of DNA // Sensing and Bio-Sensing Research. 2015. V. 4. P. 11-15.

90. Dultsev F.N., Kolosovsky E.A., Mik I.A., Lomzov A.A., Pyshnyi D.V. QCM-Based Measurement of Bond Rupture Forces in DNA Double Helices for Complementarity Sensing // Langmuir. 2014. V. 30. P. 3795-3801.

(C) 2016 by the authors; licensee Preprints, Basel, Switzerland. This article is an open access article distributed under the terms and conditions of the Creative Commons by Attribution (CC-BY) license (http://creativecommons.org/licenses/by/4.0/). 